\title{
The Effect of Luteal-Phase Support with Triptrolin Administration on Implantation and Clinical Pregnancy Rate in Assisted Reproductive Technology
}

\author{
Marzieh Aghahosseini' ${ }^{1}$, Ashraf Alleyassin'1, Leili Safdarian1, Saeedeh Gharahjeh ${ }^{1}{ }^{*}$, Hojat Saeidi1, \\ Fatemeh Sarvi' ${ }^{1}$, Sedigheh Hosseini' ${ }^{1}$, Nooshin Mohammadi ${ }^{2}$, Golamreza Roshandel ${ }^{3}$, \\ Jalal Gharajeh ${ }^{3}$ \\ ${ }^{1}$ Department of Infertility, Tehran University of Medical Sciences, Tehran, Iran \\ ${ }^{2}$ Department of Perinatology, Tehran University of Medical Sciences, Tehran, Iran \\ ${ }^{3}$ Golestan Research Center of Gastroenterology and Hepatology, Golestan University of Medical Sciences, Golestan, Iran \\ Email: *s_gharahgeh@razi.tums.ac.ir
}

How to cite this paper: Aghahosseini, M., Alleyassin, A., Safdarian, L., Gharahjeh, S., Saeidi, H., Sarvi, F., Hosseini, S., Mohammadi, N., Roshandel, G. and Gharajeh, J. (2017) The Effect of Luteal-Phase Support with Triptrolin Administration on Implantation and Clinical Pregnancy Rate in Assisted Reproductive Technology. Open Journal of Obstetrics and Gynecology, 7, 571580 .

https://doi.org/10.4236/ojog.2017.75060

Received: January 3, 2017

Accepted: May 23, 2017

Published: May 26, 2017

Copyright $\odot 2017$ by authors and Scientific Research Publishing Inc. This work is licensed under the Creative Commons Attribution International License (CC BY 4.0).

http://creativecommons.org/licenses/by/4.0/ (c) (i) Open Access

\begin{abstract}
Background: Luteal phase support with GnRH agonist administration has been shown to be effective in improving the outcome of assisted reproductive technology. The goal of this study was to evaluate the effect of single dose Triptrolin (a GnRH agonist) on the probability of the clinical pregnancy rate following embryo transfer (ET) in assisted reproductive techniques (ART). Methods: In this double blinded randomized clinical trial, 340 infertile women who were candidates for intra-cytoplasmic sperm injection (ICSI) were randomly assigned to receive GnRH agonist (Triptrolin) in the luteal phase or placebo. In the intervention group, $0.1 \mathrm{mg}$ Triptrolin was injected subcutaneously, while the control group received normal saline. The clinical pregnancy and implantation rate were compared between the two groups using chi- 2 and t-test. P-values less than 0.05 were considered significant. The registration number of this clinical trial is IRCT 2014030916912N1. Results: Administration of $0.1 \mathrm{mg}$ Triptrolin on day 6 after oocyte pick up showed no superiority over placebo in implantation $(16.9 \%-14 \%, \mathrm{P}=0.40)$ and clinical pregnancy rates $(32 \%-29 \%, \mathrm{P}=0.66)$, but the rate of clinical pregnancy was higher in women who were below 27 years of age and those with PCO. Conclusion: Administration of Triptrolin was not superior to placebo for luteal phase support.
\end{abstract}

\section{Keywords}

Luteal Phase Support, GnRH Agonist, Implantation Rate, Clinical Pregnancy 


\section{Introduction}

Luteal phase defect (LPD) either results from deficient P4 (progesterone) secretion or suboptimal responsiveness of the endometrium to normal P4 secretion [1]. The main reasons for LPD are proposed to be adverse effects of controlled ovarian stimulation (supraphysiological steroid levels, endometrial advancement), loss of LH pulsatility, and depletion of granulosa cells according to follicle aspiration [2] [3]. Previous studies have showed that luteal phase support is effective in improving the ART outcome [4] [5]. There is a need for more drugs to increase the endometrium receptivity and produce endogenous progesterone to support the luteal phase and increase the pregnancy rate.

In recent years, administration of $\mathrm{GnRH}$ agonists (Triptrolin) for luteal phase support in patients undergoing ART cycles has been considered as a favorable option [6] [7]. GnRH agonists induce LH (luteal hormone) secretion by the pituitary cells; therefore, the corpus luteum function could be supported [8]. On the other hand, GnRH agonists (Triptrolin) can modulate the endometrial receptors of GnRH and improve the implantation rate [9] [10]. However, limited studies have evaluated the effects of GnRH agonist administration for luteal phase support. We designed this randomized double blind controlled trial to evaluate the effect of the single dose of a GnRH agonist (Triptrolin) for luteal phase support on the probability of clinical pregnancy rate following embryo transfer (ET).

\section{Patients and Methods}

The study protocol was approved by the Ethics Committee of Tehran University of Medical Sciences and was registered in Iranian Clinical Registry database (IRCT 2014030916912N1).

All patients were asked to fill in an informed consent form. The physicians that evaluated the pregnancy outcome and patients were blind to the patient groups.

The study population consisted of all infertile couples who wished to undergo intracytoplasmic sperm injection (ICSI) for the first time at Omid Clinic, Tehran, between June and December 2014. During this time period, 340 eligible cases were recruited and randomly assigned into intervention or control group. Couples selected for an ICSI attempt using antagonist ovarian stimulation protocol were randomized between a luteal-phase GnRH agonist (Triptrolin) group and a placebo group. We randomly allocate our groups by Excel software using Rand Between order. Sealed envelopes with treatment allocation instructions were opened on the day of embryo transfer by a nurse to assign participants to their groups. The gynecologist and the embryologist team performing the ART were blinded to group assignment.

In the intervention group, women were given a single dose of a $\mathrm{GnRH}$ agonist (Triptrolin) 6 days after ICSI ( 3 days after embryo transfer) and the other group received placebo at the same time after ICSI.

The clinical pregnancy rate was chosen as the main outcome measure. The sample size was calculated to detect differences in the clinical pregnancy rate from 
$30 \%$ to $45 \%$. Assuming a significance level of 0.05 and a statistical power of $80 \%$, it was calculated that 170 patients were needed in each group to detect the increase.

\subsection{Participants}

Three hundred and forty couples were enrolled in this study (Figure 1). The inclusion criteria were normal responder and PCO Syndrome (evidence of hyperandrogenemia or hyperandrogenism with ovulation disorder not attributed to other causes) [1] [11] [12]. Exclusion criteria were ART with donation gamete, azospermia, poor responder defined as female age more than 40 years, antiMüllerian hormone (AMH) less than $1.1 \mathrm{ng} / \mathrm{mL}$, uterine fibroma with pressure effect on the endometrium or sub mucosal myoma, a history of myomectomy, and a history of any previous IVF/ICSI trial.

In addition, the patient was excluded from the study if she showed symptoms of ovarian hyper stimulation syndrome (OHSS) at any time during the procedure. OHSS was diagnosed with an estradiol level $>4000 \mathrm{pg} / \mathrm{ml}$, ovaries $6-12$ $\mathrm{cm}$, and ascites by ultrasound [1] [11] [12].

\subsection{Ovarian Stimulation}

At the beginning, all cases were evaluated by primary Transvaginal ultrasound and serum measurements of FSH, LH and anti-Müllerian hormone (AMH) on the 3rd day of the menstrual cycle.

\subsection{GnRH Antagonist Protocol}

Recombinant human FSH (Gonal-F, Serono, Aubonne, Switzerland) was started on day 2 of menstrual bleeding following withdrawal of contraceptive pills (Iran Hormone Co., Iran) administered during the cycle preceding ovarian stimulation. The starting dose of rFSH was chosen according the patients' age, ovarian reserve and BMI, but further doses were determined according to subsequent ultrasound results and continued with Hmg (Menogon, Ferring, Germany). A $\mathrm{GnRH}$ antagonist (Cetrotide, Serono, Switzerland) was started on day 5 of gonadotropin therapy and continued at a daily dose of $0.25 \mathrm{mg}$ until the size of at least two dominant follicles reached $\geq 18 \mathrm{~mm}$ in diameter; then, 10,000 IU HCG (Choragon, Ferring, Germany) was administered intramuscularly.

\subsection{Assisted Reproductive Techniques (ARTs)}

Oocytes were retrieved 36 hours after HCG injection and the metaphase II oocytes were selected to ICSI. All embryos were graded on day 3 according to the Istanbul Global Consensus Scoring System [12].

Embryo transfer was performed 3 days after ICSI using a Cook embryo transfer catheter (Cook Medical Inc, USA). A maximum of three embryos were transferred under clinical touch ET.

\subsection{Luteal-Phase Supplementation}

Three days after ET or 6 days after ICSI, $0.1 \mathrm{mg}$ Triptrolin was injected subcuta- 
neously for patients in the intervention group while the women in the control group received normal saline. For all cases, $25 \mathrm{mg}$ intramuscular progesterone daily (Aburaihan Co., Tehran, Iran) was injected and $800 \mathrm{mg}$ vaginal progesterone (Cyclogest, Cox, pharmaceutical, Branstaple, UK.) was administered until the fetal cardiac activity was detected. Then, vaginal progesterone was administered until 12 weeks gestation. Embryos were graded according to Table 1 [13].

\subsection{Outcome Measures}

The serum level of $\beta$-hCG was measured 15 days after the ET procedure. The primary outcome measures were the clinical pregnancy rate and implantation rate. Control trans-vaginal sonography was performed at 6 weeks gestation. Clinical pregnancy was defined by the presence of a gestational sac with fetal heart rate (FHR) at 6 weeks gestation.

The implantation rate was calculated as the number of observed gestational sacs per transferred embryo. The abortion rate was defined as the loss of pregnancy under 20 week's gestation. Any pregnancy beyond 20 weeks gestation was considered as an ongoing pregnancy and calculated per patient undergoing embryo transfer.

The fertilization rate was defined as the proportion of all acquired embryos to all injected oocytes (MII).

\subsection{Statistical Analysis}

The differences between groups were assessed by Chi-2 test or Fisher's exact tests for categorical variables and by Mann-Whitney U-test for continuous variables. Multivariate logistic regression analysis was used for assessing the relationships between different variables and the clinical pregnancy rate. Adjusted odds ratios (OR) and their 95\% CIs were calculated. The level of significance was set at 0.05 .

\section{Results}

Infertile couples continued to be assessed for eligibility until at least 162 patients

Table 1. Consensus scoring system for cleavage-stage embryos (in addition to cell numbers).

\begin{tabular}{|c|c|c|}
\hline Grade & Rating & Description \\
\hline \multirow{3}{*}{1} & \multirow{3}{*}{ Good } & $<10 \%$ fragmentation \\
\hline & & Stage-specific cell size \\
\hline & & No multinucleation \\
\hline \multirow{3}{*}{2} & \multirow{3}{*}{ Fair } & $10 \%-25 \%$ fragmentation \\
\hline & & Stage-specific cell size for majority of cells \\
\hline & & No evidence of multinucleation \\
\hline \multirow{2}{*}{3} & \multirow{2}{*}{ Poor } & Severe fragmentation $(>25 \%)$ cell-size not stage-specific \\
\hline & & Evidence of multinucleation \\
\hline
\end{tabular}




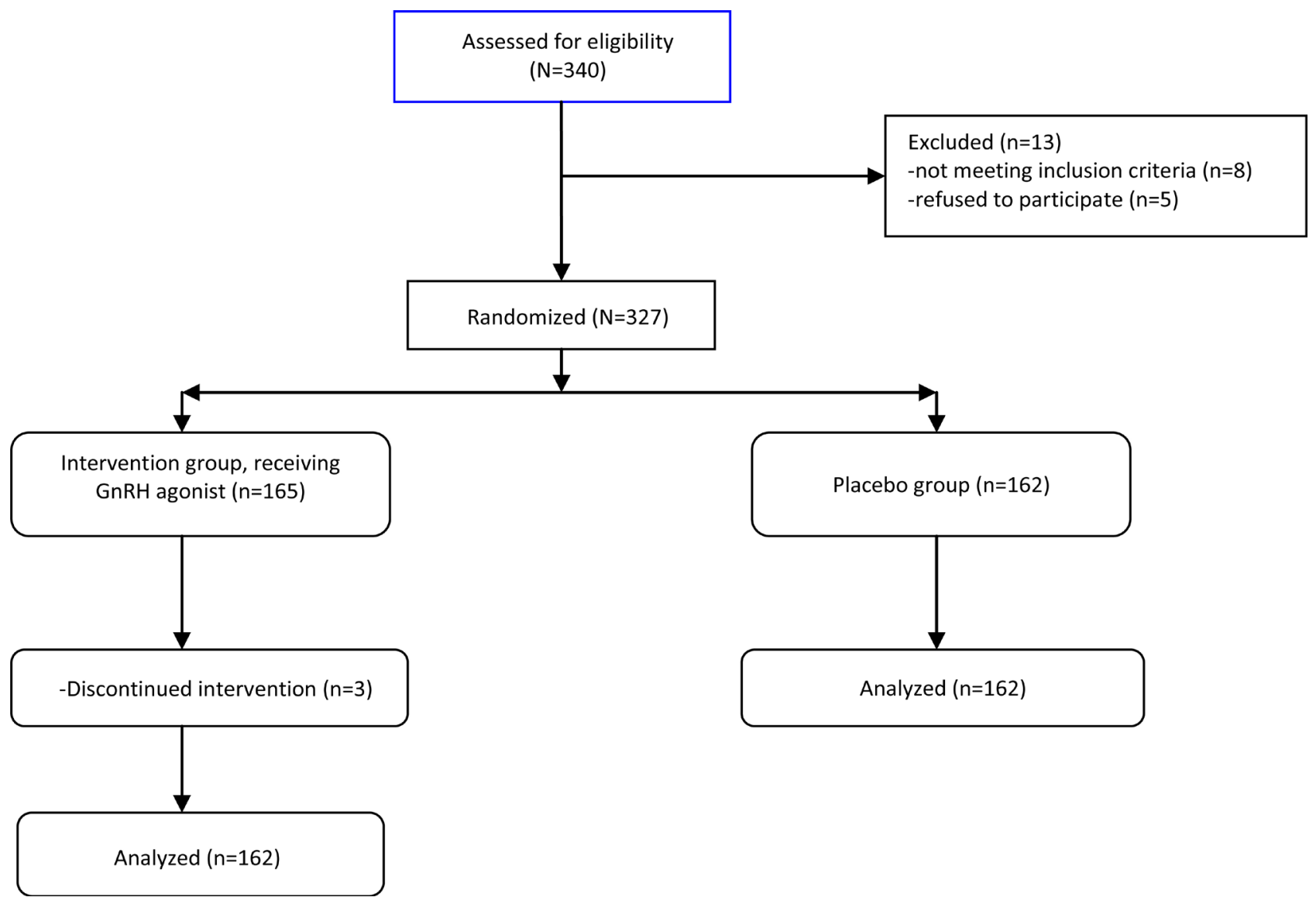

Figure 1. CONSORT diagram of the trial.

were eligible in both the treatment and the placebo arm as shown in Figure 1.

The patients in the intervention and placebo groups did not differ in their basic demographical characteristics. The implantation and clinical pregnancy rates were not higher in intervention than placebo groups (Table 2, Table 3).

As shown in Table 4, after adjusting for different variables, a positive personal history of PCO (adjusted OR $=2.46$; 95\% CI: 1.18 - 5.13) and age below 27 years (adjusted OR $=2.51 ; 95 \%$ CI: $1.13-5.56$ ) were the strongest variables related to the clinical pregnancy rate.

\section{Discussion}

The results of our study showed that the pregnancy rate did not increase with the administration of a single dose of a GnRH agonist (Triptrolin) in the luteal phase of ovulation stimulation cycles using antagonist protocols for IVF when compared with placebo. However, the clinical pregnancy rate increased by 2.5 times in women aged below 27 years as compared to their older counterparts and by 2.46 times in women in whom PCO was the reason for infertility in comparison with other reasons.

Studies by Tesarik et al. in 2006 [9], Isik et al. in 2009 [14], and Dehghani Firouzabadi in 2009 [15], as well as the results of a meta-analysis by Balista et al. in 2010 [16] showed that the clinical pregnancy rate increased following the ad- 
ministration of a single dose of GnRH agonist 6 days after ICSI. Their explanation was that GnRH agonist administration in the luteal phase 8 days after HCG injection increased LH secretion from the pituitary gland. Corpus luteum needs LH or HCG for progesterone secretion while LH is suppressed due to high estradiol levels and pituitary down-regulation by Cetrotide in the antagonist protocol and Buserelin in the long protocol. However, according to a study by

Table 2. Basic demographic and ovarian stimulation cycle characteristics of patients treated with the two ovarian stimulation protocol.

\begin{tabular}{cccc}
\hline & \multicolumn{2}{c}{ Patients' group } & \multirow{2}{*}{ P value } \\
\cline { 2 - 3 } & Triptrolin group $(\mathrm{n}=\mathbf{1 6 2})$ & Placebo group (=162) & \\
\hline Mother's age, years & $30.1 \pm 4.7$ & $30.5 \pm 4.4$ & 0.48 \\
Partner's age, years & $35.1 \pm 6.5$ & $34.5 \pm 5.2$ & 0.44 \\
BMI $\left(\mathrm{kg} / \mathrm{m}^{2}\right)$ & $25.2 \pm 3.6$ & $25.7 \pm 4$ & 0.31 \\
FSH (mIU/mL) & $4.9 \pm 1.9$ & $5.4 \pm 5.4$ & 0.20 \\
LH (mIU/mL) & $7.2 \pm 5.5$ & $8.2 \pm 6.6$ & 0.10 \\
AMH (ng/mL) & $2.5 \pm 1.5$ & $3 \pm 2.7$ & 0.05 \\
AFC & $15.5 \pm 5.7$ & $14.9 \pm 6.5$ & 0.41 \\
Number of eggs & $15.7 \pm 7.1$ & $15.2 \pm 6.5$ & 0.52 \\
Injected oocytes & $9.7 \pm 5.8$ & $10 \pm 5.8$ & 0.55 \\
Embryo retrieved & $6.4 \pm 3.5$ & $6.7 \pm 3.4$ & 0.45 \\
Fertilization rate & $83.7 \%$ & $79.5 \%$ & 0.54 \\
Cause of infertility & & & 0.08 \\
PCO & $17(10.5 \%)$ & $28(17.3 \%)$ & \\
Others & $145(89.5 \%)$ & $134(82.7 \%)$ &
\end{tabular}

Values are mean $\pm \mathrm{SD}$. The differences between the two groups are not significant $(\mathrm{P}>0.05)$ except estradiol level.

Table 3. Comparison of the pregnancy outcome between Triptrolin and placebo group.

\begin{tabular}{cccc}
\hline Patients & Triptrolin & Placebo & P VALUE \\
\hline Patient who underwent embryo transfer & 162 & 162 & \\
Embryos transferred & 379 & 406 & \\
Chemical pregnancy & $60(37 \%)$ & $70(43 \%)$ & 0.21 \\
Abortion & $9(5 \%)$ & $13(8 \%)$ & 0.35 \\
EP & $1(0.6 \%)$ & $3(1.8 \%)$ & 0.30 \\
Implantation rate & $16.9 \%$ & $14.8 \%$ & 0.80 \\
Clinical pregnancy rate & & & 0.40 \\
Per transferred embryo, N (\%) & $52 / 379(13.7 \%)$ & $47 / 406(11.5 \%)$ & 0.66 \\
Per patient undergoing embryo transfer, N (\%) & $52 / 162(32 \%)$ & $47 / 162(29 \%)$ & \\
Ongoing pregnancy rate & & & 0.78 \\
Per patient undergoing embryo transfer, N (\%) & $47 / 162(29 \%)$ & $44 / 162(27 \%)$ & \\
$\quad$ Live birth rate & & & 0.97 \\
\hline $\begin{array}{c}\text { Per patient ongoing pregnancy, N (\%) } \\
\text { M }\end{array}$ & $36 / 47(76.6 \%)$ & $34 / 44(77.3 \%)$ &
\end{tabular}


Table 4. Univariate and multivariate analysis for assessing the relationship between different variable and clinical pregnancy rate.

\begin{tabular}{|c|c|c|c|c|c|c|}
\hline \multirow{2}{*}{ Variables } & \multicolumn{3}{|c|}{ Univariate } & \multicolumn{3}{|c|}{ Multivariate } \\
\hline & Crude OR & CI & $P$ value & Adjusted OR & CI & $P$ value \\
\hline \multicolumn{7}{|l|}{ Groups } \\
\hline Triptrolin & 1.16 & $0.72-1.86$ & 0.55 & 1.40 & $0.82-2.40$ & 0.21 \\
\hline Placebo & $\mathrm{R}$ & $\mathrm{R}$ & $\mathrm{R}$ & $\mathrm{R}$ & $\mathrm{R}$ & $\mathrm{R}$ \\
\hline BMI & 1.01 & $0.95-1.08$ & 0.67 & 1.02 & $0.95-1.09$ & 0.59 \\
\hline \multicolumn{7}{|l|}{ ET } \\
\hline 2 & 0.76 & $0.47-1.23$ & 0.26 & 0.71 & $0.42-1.20$ & 0.20 \\
\hline 3 & $\mathrm{R}$ & $\mathrm{R}$ & $\mathrm{R}$ & $\mathrm{R}$ & $\mathrm{R}$ & $\mathrm{R}$ \\
\hline FSH & 1.02 & $0.96-1.07$ & 0.55 & 1.04 & $0.98-1.11$ & 0.21 \\
\hline LH & 0.96 & $0.94-1.02$ & 0.34 & 0.96 & $0.91-1.01$ & 0.11 \\
\hline $\mathrm{AMH}$ & 1.03 & $0.93-1.14$ & 0.52 & 1.01 & $0.89-1.14$ & 0.90 \\
\hline \multicolumn{7}{|c|}{ Cause infertility } \\
\hline PCO & 2.25 & $1.19-4.28$ & 0.01 & 2.46 & $1.18-5.13$ & 0.01 \\
\hline Others & $\mathrm{R}$ & $\mathrm{R}$ & $\mathrm{R}$ & $\mathrm{R}$ & $\mathrm{R}$ & $\mathrm{R}$ \\
\hline \multicolumn{7}{|l|}{ Female age } \\
\hline$>27$ & 2.43 & $1.15-5.17$ & 0.02 & 2.50 & $1.13-5.56$ & 0.02 \\
\hline $27-31$ & 1.63 & $0.78-3.41$ & 0.19 & 1.73 & $0.79-3.78$ & 0.16 \\
\hline $31-34$ & 1.55 & $0.70-3.44$ & 0.28 & 1.46 & $0.64-3.34$ & 0.37 \\
\hline$<34$ & $\mathrm{R}$ & $\mathrm{R}$ & $\mathrm{R}$ & $\mathrm{R}$ & $\mathrm{R}$ & $\mathrm{R}$ \\
\hline
\end{tabular}

$\mathrm{ET}=$ embryo transfer number.

Winslow in 1992, pituitary suppression is finished approximately one week after the last Buserelin injection [17]. Moreover, in 1996, Weisman et al. reported that the serum $\beta$ HCG level was detectable for up to one week after intramuscular injection of 10,000 units of HCG [18]. Considering the absence of LH and HCG to stimulate their receptors on the corpus luteum after oocyte pick-up, there is a need for a drug to stimulate LH from the pituitary gland. Moreover, these researchers emphasized the presence of GnRH receptors on the endometrium and embryo and believed that $\mathrm{GnRH}$ agonist injection increased the receptivity of the endometrium and the dialogue between the embryo and the endometrium, leading to increased implantation. However, a study by Ata et al. failed to show an increase in the clinical pregnancy rate following GnRH agonist injection 6 days after ICSI [3], which was in line with our finding. Ata proposed low dose GnRH agonist as the reason and argued that a medicine should have a longer half-life to create an appropriate blood level for stimulating LH secretion from the pituitary gland and GnRH receptor stimulation in the embryo and endometrium.

A study by Pirad in 2006 showed that the duration of the luteal phase was associated with the number of GnRH agonist (Buserelin) administrations in the luteal phase [19].

In patients who underwent ovulation stimulation in the antagonist cycle, triggering was done with $200 \mu \mathrm{g}$ Buserelin intranasally; in these patients, $100 \mu \mathrm{g} \mathrm{Bu}$ serelin was injected every 2 days, every day, twice a day, and three times a day in the luteal phase. The results showed LPD in patients who received $100 \mu \mathrm{g}$ Buserelin every 2 days and every day. Although the number of patients in each group 
was low, Pirad et al. showed that the duration of the luteal phase in patients who received $100 \mu \mathrm{g}$ Buserelin 3 times a day was similar to patients who were triggered with HCG and used vaginal progesterone for luteal phase support [19].

Studies by Fuji et al. in 2001 [20] and Isikoglu in 2007 [21] showed that GnRH agonist administration for 14 days from oocyte pick-up increased the clinical pregnancy rate. Therefore, studies with more accurate methodology, larger sample sizes, and modifications in drug administration methods are required in this regard.

The results of our study showed that the clinical pregnancy rate increased in women below the age of 27 and those who had PCO after receiving Triptrolin 6 days after ICSI. According to references, clinical pregnancy decreases with age and our finding may not be related to Triptrolin; however, one of the reasons for LPD is LH suppression and decreased granulose cells following oocyte pick-up (where progesterone precursor is made). In women with PCO, the level of estradiol is higher than other reasons of infertility; therefore, there is more LH suppression. On the other hand, there are GnRH receptors on granulose cells in addition to LH/HCG receptors [12] [22] and PCO patients have more granulose cells. Hence, Triptrolin one week after HCG injection increases LH secretion from the hypophysis indirectly and also directly binds to GnRH receptors on the corpus luteum and increases progesterone. We did not measure the progesterone level in the luteal phase, which was a limitation of our study. On the other hand, there are GnRH receptors on the endometrium and embryo but the effect of Triptrolin on them is a matter of debate considering its short half-life (3 - 4 hours) [3]. Therefore, it is recommended to perform a larger multicenter study to evaluate its effects on PCO patients. Moreover, studies should be conducted to evaluate the direct effect of intrauterine GnRH injection on the embryo and endometrium in the freeze cycle or the effect of administering Triptrolin at higher doses for longer periods in the fresh cycle.

\section{Acknowledgements}

This was part of the doctorate thesis dedicated to achieving the fellowship degree in infertility. The project was supported by Tehran University of Medical Sciences.

\section{Conflict of Interests}

Authors confirm no conflict of interest.

\section{Authors Contributions}

M.A, A.A, L.S and H.S contributed in Protocol/project development, S.Gh contributed in data collection and management, G.R analyzed data, F.S, S.H, N.M, J.GH and S.Gh contributed in writing and editing the manuscript.

\section{References}

[1] de Mola, J.R.L. (2014) Principles and Practice of Assisted Reproductive Technology. 
Fertility and Sterility, 102, 610. https://doi.org/10.1016/j.fertnstert.2014.06.018

[2] Granne, I. and Corfield, L. (2013) Legal, Ethical and Regulatory Aspects of Assisted Reproductive Technology (ART). Textbook of Clinical Embryology, 193.

[3] Ata, B., Yakin, K., Balaban, B. and Urman, B. (2008) GnRH Agonist Protocol Administration in the Luteal Phase in ICSI-ET Cycles Stimulated with the Long GnRH Agonistprotocol: A Randomized, Controlled Double Blind Study. Human Reproduction, 23, 668-673. https://doi.org/10.1093/humrep/dem421

[4] Nosarka, S., Kruger, T., Siebert, I. and Grové, D. (2005) Luteal Phase Support in in vitro Fertilization: Meta-Analysis of Randomized Trials. Gynecologic and Obstetric Investigation, 60, 67-74. https://doi.org/10.1159/000084546

[5] Pritts, E. and Atwood, A. (2002) Luteal Phase Support in Infertility Treatment: A Meta-Analysis of the Randomized Trials. Human Reproduction, 17, 2287-2299. https://doi.org/10.1093/humrep/17.9.2287

[6] Kashanian, M., Sariri, E., Vahdat, M., Ahmari, M., Moradi, Y. and Sheikhansari, N. (2015) A Comparison between Serum Levels of Interleukin-6 and CA125 in Patients with Endometriosis and Normal Women. Medical Journal of the Islamic Republic of Iran, 29, 280.

[7] Almassinokiani, F., Mehdizadeh, A., Sariri, E., Rezaei, M., Almasi, A., Akbari, H., et al. (2013) Effects of Simvastatin in Prevention of Pain Recurrences after Surgery for Endometriosis. Medical Science Monitor, 19, 534-539. https://doi.org/10.12659/MSM.883967

[8] Tesarik, J., Hazout, A. and Mendoza, C. (2004) Enhancement of Embryo Developmental Potential by a Single Administration of GnRH Agonist at the Time of Implantation. Human Reproduction, 19, 1176-1180.

https://doi.org/10.1093/humrep/deh235

[9] Tesarik, J., Hazout, A., Mendoza-Tesarik, R., Mendoza, N. and Mendoza, C. (2006) Beneficial Effect of Luteal-Phase GnRH Agonist Administration on Embryo Implantation after ICSI in Both GnRH Agonist- and Antagonist-Treated Ovarian Stimulation Cycles. Human Reproduction, 21, 2572-2579.

https://doi.org/10.1093/humrep/del173

[10] Haghighi, L., Hashemi, N., Moradi, Y., Barzegar, N. and Najmi, Z. (2016) The Association between Menarche Age and First Offspring Sex Ratio. Shiraz E-Medical Journal, 17.

[11] Ebner, T., Vanderzwalmen, P. and Wirleitner, B. (2015) Atlas of Vitrified Blastocysts in Human Assisted Reproduction. Cambridge University Press, Cambridge. https://doi.org/10.1017/CBO9781139696524

[12] Rao, K. (2013) Principles \& Practice of Assisted Reproductive Technology. 3 Vols, JP Medical Ltd.

[13] Rao, K.A., Carp, H. and Fischer, R. (2014) Principles and Practice of Assisted Reproductive Technology. Atlas of Human Embryology. Jaypee Brothers Medical Publishers.

[14] Isik, A.Z., Caglar, G.S., Sozen, E., Akarsu, C., Tuncay, G., Ozbicer, T., et al. (2009) Single-Dose GnRH Agonist Administration in the Luteal Phase of GnRH Antagonist Cycles: A Prospective Randomized Study. Reproductive Biomedicine Online, 19, 472-477. https://doi.org/10.1016/j.rbmo.2009.04.001

[15] Razieh, D.F., Maryam, A.R. and Nasim, T. (2009) Beneficial Effect of Luteal-Phase Gonadotropin-Releasing Hormone Agonist Administration on Implantation Rate after Intracytoplasmic Sperm Injection. Taiwanese Journal of Obstetrics and Gynecology, 48, 245-248. https://doi.org/10.1016/S1028-4559(09)60297-7

[16] Oliveira, J.B.A., Baruffi, R., Petersen, C.G., Mauri, A.L., Cavagna, M. and Franco, 
J.G. (2010) Administration of Single-Dose GnRH Agonist in the Luteal Phase in ICSI Cycles: A Meta-Analysis. Reproductive Biology and Endocrinology, 8, 107. https://doi.org/10.1186/1477-7827-8-107

[17] Winslow, K.L., Gordon, K., Williams, R.F. and Hodgen, G.D. (1992) Interval Required for Gonadotropin-Releasing Hormone-Agonistinduced Down Regulation of the Pituitary in Cynomolgus Monkeys and Duration of the Refractory State. Fertility and Sterility, 58, 1209-1214.

[18] Weissinan, A., Lurie, S., Zalel, Y., Goldchmit, R. and Shoham, Z. (1996) Human Chorionic Gonadotropin: Pharmacokinetics of Subcutaneous Administration. Gynecological Endocrinology, 10, 273-276.

https://doi.org/10.3109/09513599609012319

[19] Pirard, C., Donnez, J. and Loumaye, E. (2005) GnRH Agonist as Novel Luteal Support: Results of a Randomized, Parallel Group, Feasibility Study Using Intranasal Administration of Buserelin. Human Reproduction, 20, 1798-1804. https://doi.org/10.1093/humrep/deh830

[20] Fujii, S., Sato, S., Fukui, A., Kimura, H., Kasai, G. and Saito, Y. (2001) Continuous Administration of Gonadotrophin-Releasing Hormone Agonist during the Luteal Phase in IVF. Human Reproduction, 16, 1671-1675. https://doi.org/10.1093/humrep/16.8.1671

[21] Isikoglu, M., Ozgur, K. and Oehninger, S. (2007) Extension of GnRH Agonist through the Luteal Phase to Improve the Outcome of Intracytoplasmic Sperm Injection. The Journal of Reproductive Medicine, 52, 639-644.

[22] Reshef, E., Lei, Z., Rao, C.V., Pridham, D., Chegini, N. and Luborsky, J. (1990) The Presence of Gonadotropin Receptors in Nonpregnant Human Uterus, Human Placenta, Fetal Membranes, and Decidua. The Journal of Clinical Endocrinology \& Metabolism, 70, 421-430. https://doi.org/10.1210/jcem-70-2-421

\section{Submit or recommend next manuscript to SCIRP and we will provide best service for you:}

Accepting pre-submission inquiries through Email, Facebook, LinkedIn, Twitter, etc. A wide selection of journals (inclusive of 9 subjects, more than 200 journals)

Providing 24-hour high-quality service

User-friendly online submission system

Fair and swift peer-review system

Efficient typesetting and proofreading procedure

Display of the result of downloads and visits, as well as the number of cited articles

Maximum dissemination of your research work

Submit your manuscript at: http://papersubmission.scirp.org/

Or contact ojog@scirp.org 